\title{
DESIGN OF STRUCTURE OF TENSION LEG PLATFORM FOR 6 MW OFFSHORE WIND TURBINE BASED ON FEM ANALYSIS
}

\author{
Jędrzej Żywicki \\ Paweł Dymarski \\ Ewelina Ciba \\ Czesław Dymarski \\ Gdansk University of Technology, Poland
}

\begin{abstract}
The article presents the calculation and design stages of the TLP platform serving as a supporting construction of a $6 \mathrm{MW}$ offshore wind turbine. This platform is designed to anchor at sea at a depth of $60 \mathrm{~m}$. The authors presented the method of parameterization and optimization of the hull geometry. For the two selected geometry variants, the load and motion calculations of the platform subjected to wind, wave and current under 50-year storm conditions were performed. The maximum load on the structure was determined in these extreme storm conditions. For these loads, the MES calculation of the designed platform was performed for the selected variant. Authors have presented a method for calculating maximum wind, wave and current stresses on the structure during the worst storm in the past 50 years. For these loads the MES endurance calculations of the designed platform were made. Based on the results of these calculations, the required structural changes and recalculations have been made in succession to the structural design of the platform, which meets the design requirements and has the required ad hoc strength. The article contains stress analysis in "difficult" nodes of constructions and discusses ways of solving their problems. The work is part of the WIND-TU-PLA project from the NCBR Research Agreement (Agreement No. MARTECII / 1/2014).
\end{abstract}

Keywords: offshore wind turbine, TLP, support structure, FEM

\section{INTRODUCTION}

In recent years, more and more rapid development in the field of offshore wind turbines has been observed. More attention is being paid to reliability, durability and energy efficiency. For this purpose, specialized software using FEM and CFD methods $[1,2,3,4,5,6,7]$ is used. With estimates of the analysis results, that for waters deeper than 50 meters, cost-effective solution is the use of floating structures. There are already solutions of floating structures, which are going to be used on an industrial scale, mainly buoyancy stabilized [8] or ballast stabilized $[9,10]$ structures. In recent years, there are more and more publications including computational analysis of TLP-type of foundation systems for offshore wind turbines $[11,12,13]$
The works presented in this article were carried out under the "WIND-TU-PLA" acronym project from the MARTEC II Era-Net program. The project's objective is to develop foundation systems for the southern Baltic basin where areas have been pre-designated where wind turbines are to be installed.

This article presents a design dedicated for $50 \mathrm{~m}+$ depth water. The subject of analysis is the Tension Leg Platform. According to the assumptions, it is a buoyancy structure, designed for a depth of $60 \mathrm{~m}$, fixed to the bottom by tight ties and allows the installation of a turbine of $6 \mathrm{MW}$.

The available articles $[11,12,13]$, as well as the classification societies [14], show that many issues related to the design of 
floating platforms (and in particular TLP structures) still require improvement or refinement.

Due to the fact that in industry magazines hardly any detailed information about the design and strength calculations of this type of construction can be found, the authors undertook to solve this task within the framework of the above project. The calculations take into account all the significant loads of an object, namely the weight of the structure, including the turbine tower, as well as hydrostatic forces and aerodynamic and hydrodynamic forces acting on the whole object during extreme operating conditions, restoring forces of the anchorage system and the inertia force acting on the mass of the structure during accelerated movement.

This article presents the stages of designing a TLP structure based on an ad hoc strength analysis. The analysis of fatigue strength, due to a much wider range of work, will be presented in a separate publication.
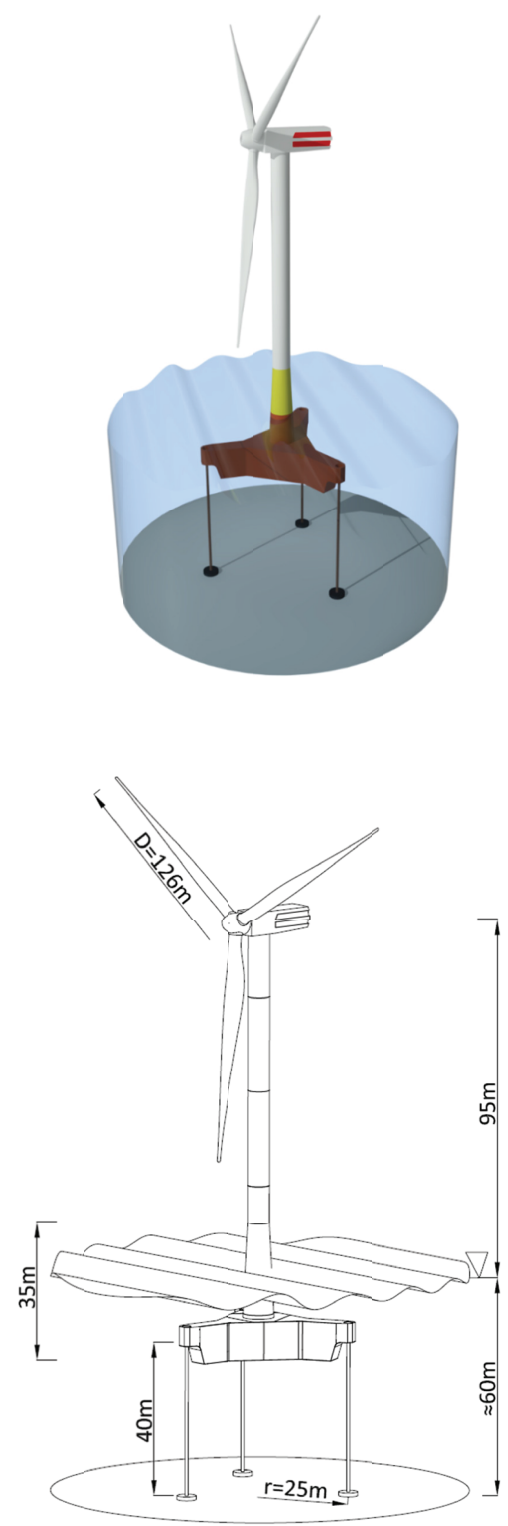

Fig. 1. Main design dimensions.

\section{HULL GEOMETRY DESIGN. PARAMETRIC OPTIMIZATION}

The visualization of the model and the main geometrical assumptions are shown in Figure 1. The design assumption was to install a $6 \mathrm{MW}$ turbine, pre-modelling on the SENVION 6.2M turbine [15]. Table 1 shows the basic technical parameters of the reference turbine as well as the 5MW (NREL Reference Wind Turbine) [16] and the values that were used for the test calculations.

Tab. 1 . The main characteristics of the wind turbines

\begin{tabular}{|l|c|c|c|}
\hline & Design [18] & NREL 5MW & Test case \\
\hline Rotor Type & Senvion 6.2M & NREL 5MW & NREL 5MW \\
\hline Rated Power & $6.15 \mathrm{MW}$ & $5 \mathrm{MW}$ & $5 \mathrm{MW}$ \\
\hline Cut in Wind Speed & $3.5 \mathrm{~m} / \mathrm{s}$ & $3.0 \mathrm{~m} / \mathrm{s}$ & - \\
\hline Rated Wind Speed & $14.0 \mathrm{~m} / \mathrm{s}$ & $11.4 \mathrm{~m} / \mathrm{s}$ & $11.4 \mathrm{~m} / \mathrm{s}^{*}$ \\
\hline Cut out Wind Speed & $30 \mathrm{~m} / \mathrm{s}$ & $25 \mathrm{~m} / \mathrm{s}$ & $25 \mathrm{~m} / \mathrm{s}^{* *}$ \\
\hline Rotor Diameter & $126 \mathrm{~m}$ & $126 \mathrm{~m}$ & $126 \mathrm{~m}$ \\
\hline $\begin{array}{l}\text { Rotor Operational } \\
\text { Interval }\end{array}$ & $7.7-12.1 \mathrm{rpm}$ & $6.9-12.1 \mathrm{rpm}$ & $12.1 \mathrm{rpm}$ \\
\hline $\begin{array}{l}\text { Thrust coefficient } \\
\text { (rated) C }\end{array}$ T.114m/s & Not available & 0.730 & $0.730^{*}$ \\
\hline $\begin{array}{l}\text { Thrust coefficient (cut } \\
\text { out) C } \mathrm{T}_{\text {,25 } / \mathrm{s} / \mathrm{s}}\end{array}$ & Not available & 0.074 & $0.074^{* *}$ \\
\hline Rotor+Nacelle Mass & $460 \mathrm{t}$ & $350 \mathrm{t}$ & $460 \mathrm{t}$ \\
\hline $\begin{array}{l}\text { Tower Height } \\
95 \mathrm{~m}\end{array}$ & $90 \mathrm{~m}$ & $95 \mathrm{~m}$ \\
\hline
\end{tabular}

* Calculations using the simplified (parametric) method, 1 DoF

${ }^{*}$ Calculations were made using a method based on the Morison equation, in six degrees of freedom, taking into account the stiffness / elasticity of the leg (s)

In order to determine the optimal dimensions of the platform, a simplified parametric analysis was carried out, influenced by the shape parameters: the height of the pontoons $H_{a}$, the volume displacement $V_{b}$ and the length of the tendons for the main parameters describing the dynamics of the platform. The main geometry parameters of the platforms are shown in Figure 2.



Fig. 2. Parameters describing the geometry of the platform. 
The computational model used for parametric analysis is based on the equation of motion along the horizontal axis $\mathrm{Ox}$, which coincides with the direction of the force (wind direction and wave direction) [17]. Equation (1) is based on the second principle of dynamics, with the mass of the structure being increased by the mass of added water. On the right side of the equation there is the force of resistance, proportional to the square of the velocity of the body relative to water, and a part representing the force arising from the wave action of the body.

$$
\begin{array}{r}
\left(m+m_{a}\right) \ddot{x}=\frac{1}{2} \rho C_{D} A_{p}|U-\dot{x}|(U-\dot{x})+ \\
+\left(\rho V_{b}+m_{a}\right) \frac{\partial U}{\partial t}+F_{x, \text { aero }}+F_{x, \text { rest }}
\end{array}
$$

where: $m_{a}$ - added mass, $\rho$ - density of sea water, $C_{D}-$ drag coefficient of submerged part of the structure [17], $A_{p}$ - projected Area of the structure on a plane normal to the motion direction $(O x), U$ - velocity of surrounding water (based on Airy wave theory), $F_{x, a e r o}$ - total aerodynamic force, $F_{x, \text { rest }}$ - restoring force due to the mooring system, given by the following formula:

$$
F_{x, r e s t}=\frac{x}{L_{t}}\left(\rho g V_{b}-m g\right),
$$

where $g$ is a gravity.

Added mass ma and drag coefficient $C_{D}$ has been approximated using simple empirical formulas for $2 \mathrm{D}$ sections [17]. Added mass for the pontoon $m_{a, a}$ and for a cylindrical column $m_{a, c}$ are calculated from the formulas:

$$
\begin{aligned}
& m_{a, a}=c_{1} \rho \pi \frac{H_{a}^{2}}{4} l_{a, p} ; \\
& m_{a, c}=\rho \pi \frac{D_{c}^{2}}{4} h_{c, s},
\end{aligned}
$$

where: $D_{c}$ - column diameter, $c_{1}$ - coefficient dependent on the proportion of rectangular pontoon section, for a section close to the square $c_{1}=1.51$.

$l_{a, p}$ - the total length of the pontoon, projected on a plane perpendicular to the direction of inflow, $h_{c, s}-$ the height of the immersed part of the column.

Parameters have been selected in such a way that, by changing them, they have a specific effect on the dynamics of the object. By analysing the parts of equation (1), and equation (2) and equation (3a), one can conclude that:

- Changing the hull volume $V_{b}$ will result in an increase in the forcing force (the second part to the right of the equation (1)) and the increase in the restoring force (equation (2)). Changing the restoring force will change the frequency of the oscillation $\omega_{0}$ of the platform,

- Changing the height of the pontoon $H_{a}$ will change the mass of the accompanying water (equation (3a)) and change the resistance force by changing the surface $A_{p}$ (the first part of the right side of equation (1). The change in the force of resistance will also change the force of the oscillation of the object.
- Changing the length of the $L_{t}$ strings (by appropriate pontoon formation or changing the depth of the water area d) will result in a change in the restoring force characteristics (equation (2)), and hence the change in $\omega_{0}$.

Calculations were made for a wave corresponding to a 50-year storm: $H_{s}=9.01 \mathrm{~m}, T_{p}=11.3 \mathrm{~s}$ [20], assuming unfavourable wind force $U_{w}=11.4 \mathrm{~m} / \mathrm{s}$, because the thrust coefficient of the turbine was $C_{T, 11.4 m / S}=0.73$ (see table 1). These are the operating conditions at which the thrust on the turbine reaches its maximum value.

As a result of parametric analysis, the maximum amplitudes of the acceleration (longitudinal) and amplitude of the forces in the legs were obtained.

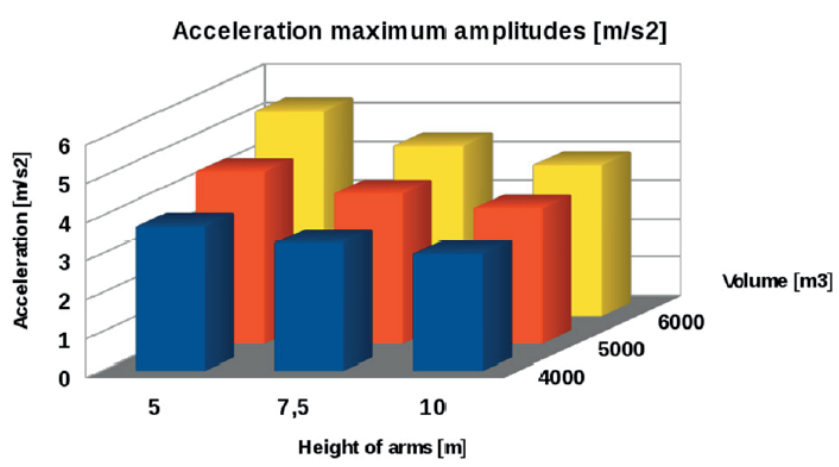

Fig. 3. Maximum amplitudes of horizontal acceleration as a function of $\mathrm{H}_{a}$ and $V_{b} . L_{t}=45 \mathrm{~m} ; r_{t}=25 \mathrm{~m} ; d=60 \mathrm{~m} ; T_{0}=20 \mathrm{~m}$.

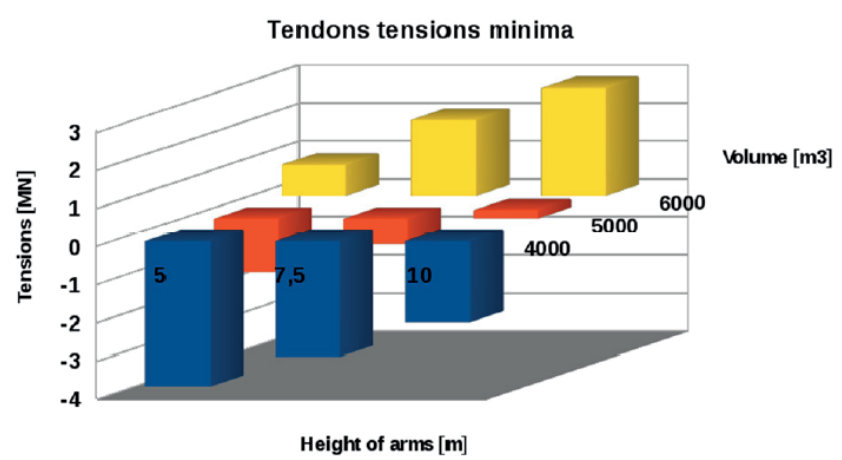

Fig. 4. Minima of tendons tensions as a function of $H_{a}$ and $V_{b}$. Negative values, mean compressive strength of tendons (loss of stability). $L_{t}=45 \mathrm{~m}$; $r_{t}=25 \mathrm{~m} ; d=60 \mathrm{~m} ; T_{0}=20 \mathrm{~m}$

Figures 3 and 4 show graphs of accelerations and minimum forces in legs as a function of the height of the arms $H_{a}$ and volume displacement $V_{b}$. The optimal solution is characterized by minimum amplitudes of acceleration (less construction loads). The correctness of the solution is that the forces in the legs are always stretching, because in the case of compression, as shown in Figure 7c, the platform will lose its stability and begin to turn over. Taking into account the above limitations, two solutions were chosen from the area of permissible solutions (Table 2, Figure 5), with the weight 
of both variants estimated on the basis of the pre-selected plating thickness assuming that the mass of the stiffeners and girders is about $20 \%$ of the plating weight.

Tab. 2. Main parameters of selected platform variants

\begin{tabular}{|l|c|c|}
\hline & TLP 1_5 & TLP 2_1 \\
\hline $\begin{array}{l}\text { Volume of submerged part of the platform, } \\
V_{b}\end{array}$ & $5360 \mathrm{~m}^{3}$ & $5500 \mathrm{~m}^{3}$ \\
\hline (Mean) height of arms (pontoons), $H_{a}$ & $7.64 \mathrm{~m}$ & $8.97 \mathrm{~m}$ \\
\hline Length of tendons (legs), $L_{t}$ & $42.4 \mathrm{~m}$ & $47.4 \mathrm{~m}$ \\
\hline $\begin{array}{l}\text { Radius of tendons distribution, } r_{t} \\
\begin{array}{l}\text { Mass of the structure (first approximation), } \\
m\end{array}\end{array}$ & $1800 \mathrm{t}$ & $1900 \mathrm{t}$ \\
\hline
\end{tabular}


TLP 2_1

Fig. 5. Visualization of the discussed platform variants.

Both TLP platform variants have been subjected to detailed computational analysis using Morison's [17, 18] software, Boundary Element Method, and RANSE-CFD.

A quick and relatively accurate method is to calculate the motion using the Morison equation. The structure is divided into segments, (based on the literature [17]) for which the coefficients of resistance and the added mass coefficient are determined. The simplified hydrodynamic model (segmentation) is shown in Figure 6. The hydrodynamic force $y 1$ component in the local coordinate system (Figure 6), on the $i$-th segment, is calculated using the formula [21]:

$$
\begin{aligned}
& F_{y 1, i}=\frac{1}{2} C_{D} \rho A_{p}\left|w-\dot{y}_{1}\right|\left(w-\dot{y}_{1}\right)+ \\
& +\rho V_{b}\left(1+C_{A}\right)\left[\frac{\partial w}{\partial t}+\left(w-\dot{y}_{1}\right) \frac{\partial w}{\partial y_{1}}\right]-\rho V_{b} C_{A} \ddot{y}_{1},
\end{aligned}
$$

where $C_{D}-$ drag coefficient on the $y_{1}$ (local coordinate system), $\rho$ - fluid density, $A_{p}$ - the surface segment on the direction $y_{1}, w$ - the velocity component for the water on the direction $y_{1}, V_{b}$ - segment volume, $C_{A}$ - ratio of mass of accompanying water, $\dot{y}_{1}, \ddot{y}_{1}$ - velocity and acceleration of the segment in direction $y_{1}$.

The composition of the hydrodynamic force $z_{1}$ is calculated similarly.

Designated forces are transformed into the global coordinate system and to the system associated with the object. Based on the knowledge of the forces and positions of the segments, the total moment of these forces is calculated for the whole object. Knowing the forces and moments allows to solve the system of equations describing the movement of an object (in six degrees of freedom).

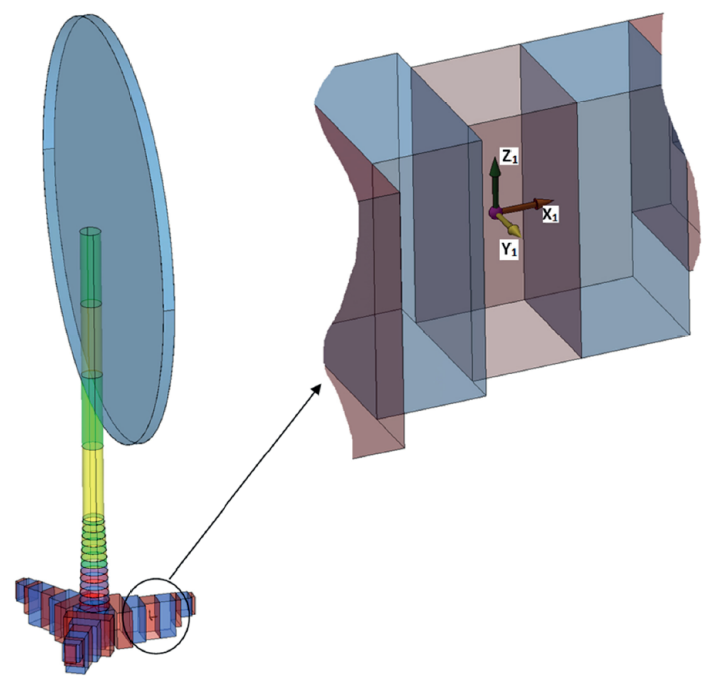

Fig. 6. Division of structure (incl. Turbine) into segments for which forces are calculated (see equation 1) with the local system shown.

Calculations, like the above, were performed for 50-year storm conditions [18]. However, due to the fact that, at high amplitudes of motion, the platform lost stability at the maximum rated wind speed $\left(U_{\mathrm{w}}=11.4 \mathrm{~m} / \mathrm{s} ; C_{\mathrm{T}, 11.4 / \mathrm{s}}=0.73\right)$. It was decided that the calculations would be performed for the conditions $U_{\mathrm{w}}=25 \mathrm{~m} / \mathrm{s}$, with thrust coefficient $C_{\mathrm{T}, 25 \mathrm{~m} / \mathrm{s}}=0.074$. It is envisaged that under extreme wave conditions, the wind turbine will operate at a reduced power setting of $\sim 8 \mathrm{~m} / \mathrm{s}$ to $\sim 25 \mathrm{~m} / \mathrm{s}$ in order to reduce the thrust.

Motion charts of both platforms (position versus time) are shown in Figures $7 \mathrm{a}, 7 \mathrm{~d}$. They show the waveform, acceleration, and force functions of the platform during the first 1200 seconds of a one-hour simulation. It is clear from the above that the amplitudes of these values are smaller for 


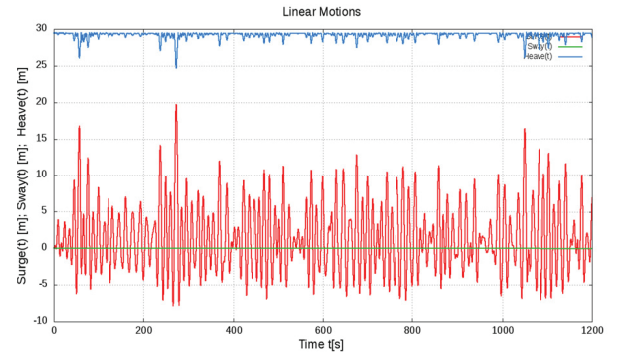

a)

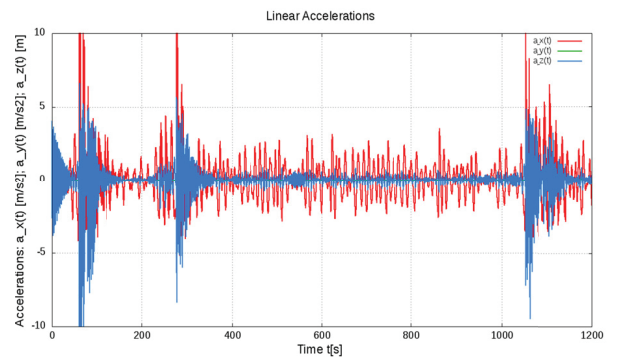

b)

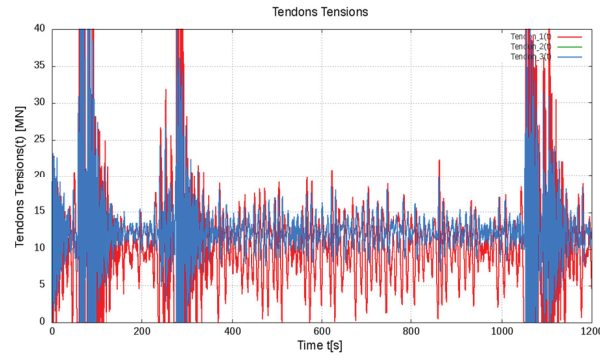

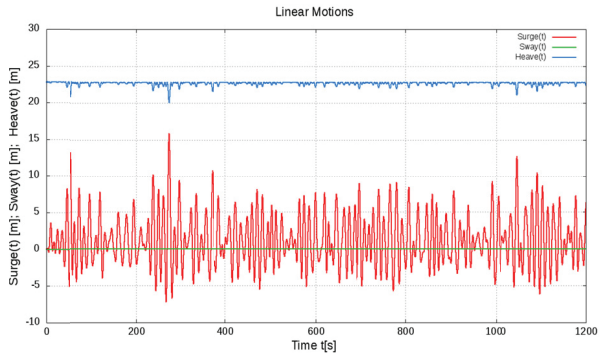

d)

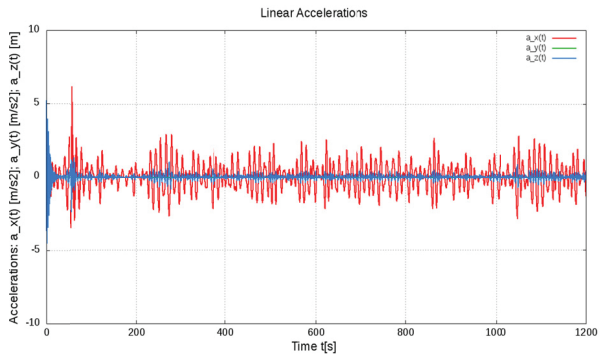

e)

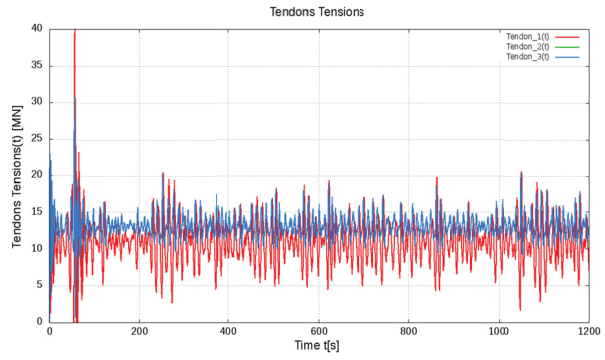

f)

Fig. 7. Graphs of displacement, acceleration and forces of the tendons to the TLP 15 of the $(a, b, c)$ and TLP 2_1 (d, e, f). Graphs were made for 1200 seconds of simulation.

platform 2_1 than for 15. Therefore, geometric parameters of variant 2_1 were chosen as assumptions for the design.

For the design of the platform construction, it was necessary to select a load system for which the design would be maximized.

The graphs shown in Figure 7 include the first 1200 seconds of the simulation. Based on the results for the full hour, a point was chosen for the time at which the reaction forces in the legs of the platform (one leg) would reach the maximum.

The resulting load distribution along the vertical axis of the structure is shown in Fig. 10.

\section{DESCRIPTION OF THE PRELIMINARY DESIGN}

The illustrated support structure was designed as a Tension Leg Platform. The main part of the structure is an underwater tricot fuselage with a centrally located column on which a tower with a wind turbine is attached. The underwater volume of about $5500 \mathrm{~m}^{3}$, the height of the arms, the length of the anchor rods were chosen so that despite the assumed loads the construction of the tendons was always stressed - stretched. The draft is $20 \mathrm{~m}$. The hull height of the regular platform is $10 \mathrm{~m}$. At the ends of the arms $25 \mathrm{~m}$ apart from the centre of the main column there are string fixing nodes with which the platform is fixed to the bottom. A conical column with a base diameter of $8 \mathrm{~m}$ is ended with a $5.5 \mathrm{~m}$ diameter fixing flange at a height of $15 \mathrm{~m}$ above the free surface area. The whole structure is made of steel. The weight of the initial variant of the platform itself is 1430 t. Figure 8 shows the prefabrication system of the construction variant together with the detail of the thicknesses of the individual components.

As the tendons, pipes having an outer diameter of 800 $\mathrm{mm}$ and a wall thickness of $40 \mathrm{~mm}$ are proposed. This type of tendon offers benefits in terms of relatively low prices compared to e.g. chains and ease of transport by towing them as displacement elements. One of the problems faced by the concept makers was to fix rigid strands to the platform hull. Based on preliminary analyses, it was determined that 




Fig. 8. Preliminary design of the structure.

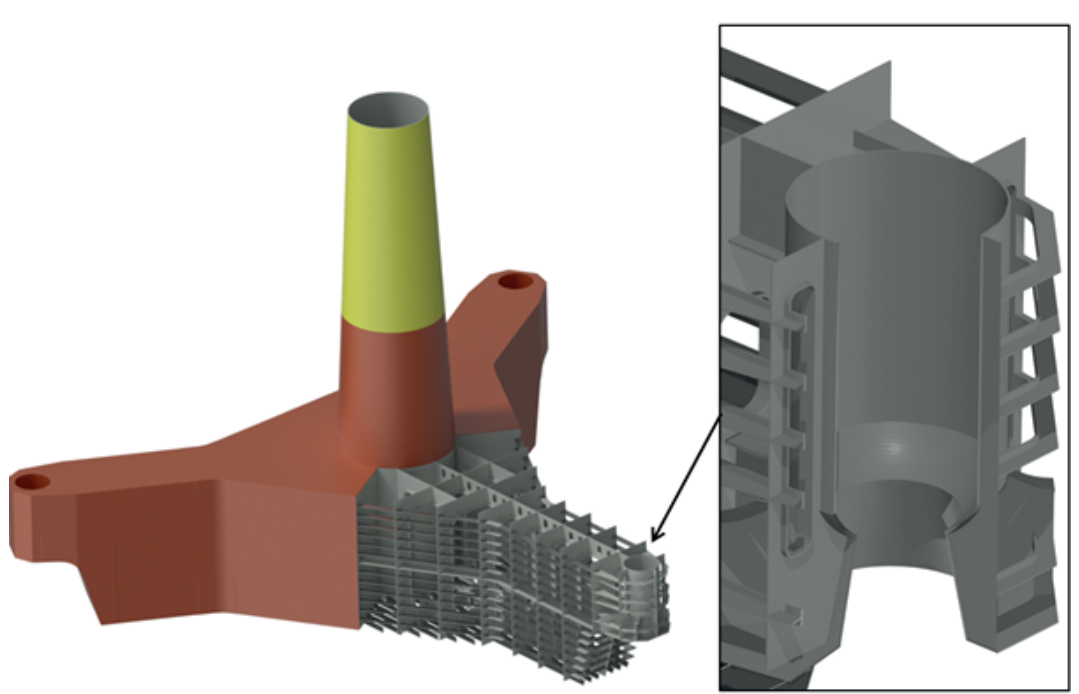

Figure 9. Platform solid model.

attaching the pipes to the hull should allow the tendon to tilt at an angle of $17^{\circ}$ from the vertical. As part of this task, the concept of a plain bearing has been developed to allow the platform to move in any direction. The fixation assumes the construction of a bearing with a polymeric shell that is part of the sphere. The materials used allow the surface pressure of $70 \mathrm{MPa}$, the contact surface is selected so as not to exceed this value even under extreme operating conditions. The final part of the platform arms has been designed to allow the assembly of the bearing components and ultimately enable the anchoring process of the platform. Figure 9 shows the solid model of the platform showing the fragment of the spherical canopy that is luminaire for the polymer bearing bush. From the bottom it connects to a specially shaped cone allowing the pipe to move freely and to pivot at a predetermined angle. From the upper deck, access to the bearing allows a steel sleeve with a diameter of $2400 \mathrm{~mm}$. The whole node was reinforced by radial stiffeners. The method of bearing and anchoring process has been developed for internal project reports, but is not discussed in more detail in this article.

\section{LOAD AND OPERATING CONDITIONS OF THE SUPPORT STRUCTURE}

The following load and operating conditions of the support structure are the same for each stage of the modification of the construction geometry shown in the work. Presented results of individual simulations were obtained for the following assumptions. As previously mentioned, the authors assume that the structure will be located in the Baltic Sea area at a depth of 60 $\mathrm{m}$. The top flange to which the column will be mounted is located at a height of $15 \mathrm{~m}$ above the water surface. Structural loads derived from environmental conditions were calculated by hydromechanical simulation taking into account the most unfavourable conditions corresponding to the "50-year storm in the Baltic Sea" [18]. The most unfavourable conditions are considered to be the load system that causes maximum stress in one of the anchor anchoring strings of the platform, while in the opposite legs the stresses reaches the minimum. This situation is most often the case when the forces of inertia caused by the accelerated motion of the platform acting on the massive elements (nacelle, rotor and tower) have a vector worthy of the direction of the aerodynamic load generated mainly on the turbine.

The technical characteristics of the turbine used to determine the foundation load are shown in Table 3:

Based on the hydromechanical simulation described in Chapter 2, the course of horizontal load derived from currents and waves and the wind as a function of the height of the object is determined. For computation, the MES model was divided into segments that are the same as for hydromechanical simulation. Thanks to this solution, the model can be easily loaded by applying the average values of the horizontal load obtained from the hydromechanical calculations to the given 
area of construction. The zero altitude was assumed at the level of the water mirror. The value of the continuous load acting on the height of the structure is shown in Figure 10.

Tab. 3. Technical parameters of the turbine

\begin{tabular}{|l|c|}
\hline Turbine power: & $6 \mathrm{MW}$ \\
\hline The height of the turbine hub MASL & $95 \mathrm{~m}$ \\
\hline Turbine diameter & $126 \mathrm{~m}$ \\
\hline Mass of nacelle and rotor & $462 \mathrm{t}$ \\
\hline Column mass & $458 \mathrm{t}$ \\
\hline
\end{tabular}

A significant factor affecting load is the acceleration of the horizontal movement of the structure due to aerodynamic and hydrodynamic forces and forces from the anchorage system. The maximum acceleration from a one-hour hydromechanical simulation determined from the motion equation for an irregular wave was $3.41 \mathrm{~m} / \mathrm{s}^{2}$, which was read from the graph shown in Figure 6e.

Hydrostatic pressure of seawater acts on the structure from $+10 \mathrm{~m}$ from the average water level (wave crest) to the bottom of the structure $(\mathrm{z}=-20 \mathrm{~m})$. The sea water density was taken as $1026 \mathrm{~kg} / \mathrm{m}^{3}$. The adopted load model is designed to simulate conditions where the wave crest reaches a height of approximately $10 \mathrm{~m}$ at high waves, which results in a significantly higher hydrostatic pressure on the structure than in the absence of waves.

Figure 10 shows the forces from the turbine's thrust and the inertial forces acting on the nacelle and rotor masses that are present in the discrete model (FEM) in the form of concentrated force. The drawing does not show forces from the anchoring system, as they appear in the model as responses on the supports.
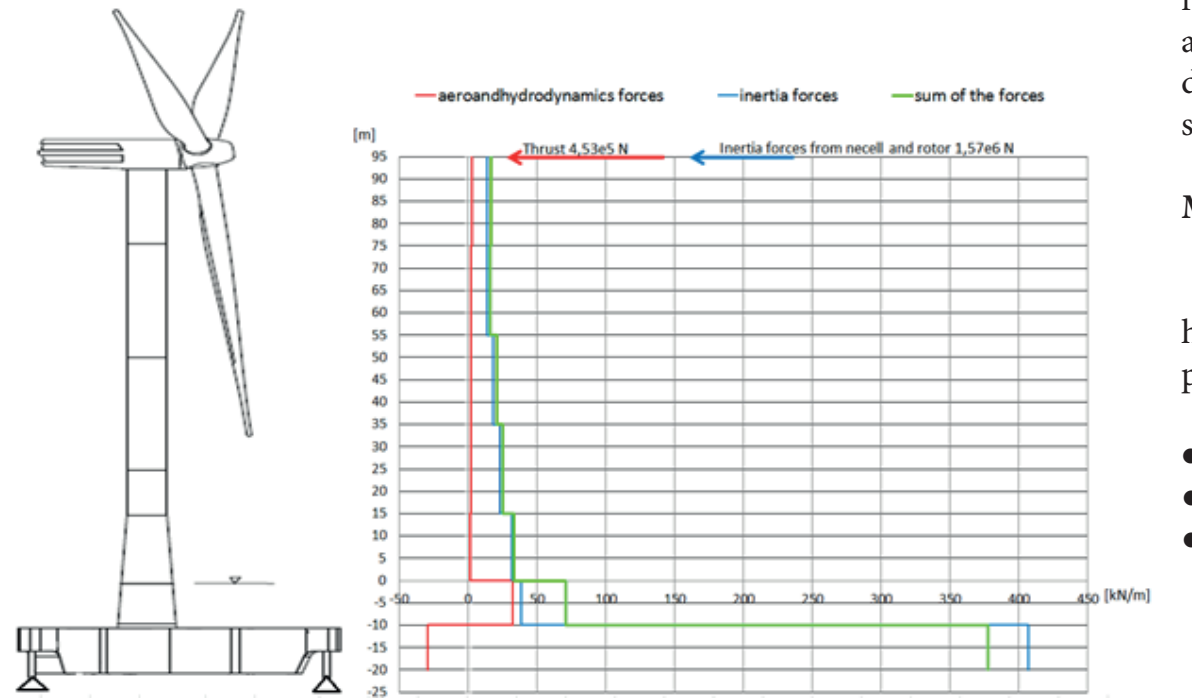

Fig. 10. Load acting on platform and tower.

\section{MES MODEL}

The surface model of the structure shown in Figure 8 was created in Autodesk Inwentor. Next, the geometry was imported into HyperMesh, where the FEM model was built. The hull, together with the internal design elements, was mapped with first-order quadrilateral and quadrilateral elements with a mean size of $90 \mathrm{~mm}$. Due to the fact that the entire structure is modelled, the platform superstructure with the tower was modelled with $200 \mathrm{~mm}$ elements, which significantly reduced the total number of components. The elements used for the first iteration are summarized in Table 4, the grid fragments shown in Figure 11.

Tab. 4

\begin{tabular}{|c|c|c|c|c|}
\hline \multirow{2}{*}{} & \multicolumn{2}{|c|}{ 2D elements } & 1D elements & $\begin{array}{c}\text { Degrees of } \\
\text { freedom }\end{array}$ \\
\cline { 2 - 5 } & Square & Triangular & $\begin{array}{c}\text { Perfectly } \\
\text { Rigid }\end{array}$ & \\
\hline Number & 694579 & 10133 & 2129 & 4144783 \\
\hline Average size & $90 / 200$ & $90 / 200$ & 2750 & - \\
\hline
\end{tabular}

In order to apply forces from the turbine's thrust and the mass of the nacelle and rotor on the top of the column - 95m above the level of the free surface, a central node was created. It has been modeled by connecting nodes on the circumference of the top edge of the column in one central node with rigid elements. Below is the model of support. At the end of each of the platform arms there is a fragment of the sphere that is ultimately a spherical ball joint that connects the platform with a tight string. In the centre of the sphere with a radius of $1400 \mathrm{~mm}$ a central node has been formed, where all the nodes of the elements on the surface of the sphere are connected by rigids. Thanks to this solution, three nodes were created, in which the degree of freedom of the model was appropriately removed. The arm node in the $\mathrm{Y}$ direction has been locked so as to prevent movement in the three directions $\mathrm{X}, \mathrm{Y}, \mathrm{Z}$ and rotating movement relative to the vertical axis, while the other two nodes have been disabled to move in the $\mathrm{Z}$ direction. The solutions described are shown in Figure 11.

\section{MODEL THE MATERIAL}

A linear-resilient material model has been adopted with the following properties:

- $\quad$ Young's module $\mathrm{E}=210 \mathrm{GPa}$

- Poisson's number $v=0.3$

- Density $\rho=7860 \mathrm{~kg} / \mathrm{m}^{3}$ 


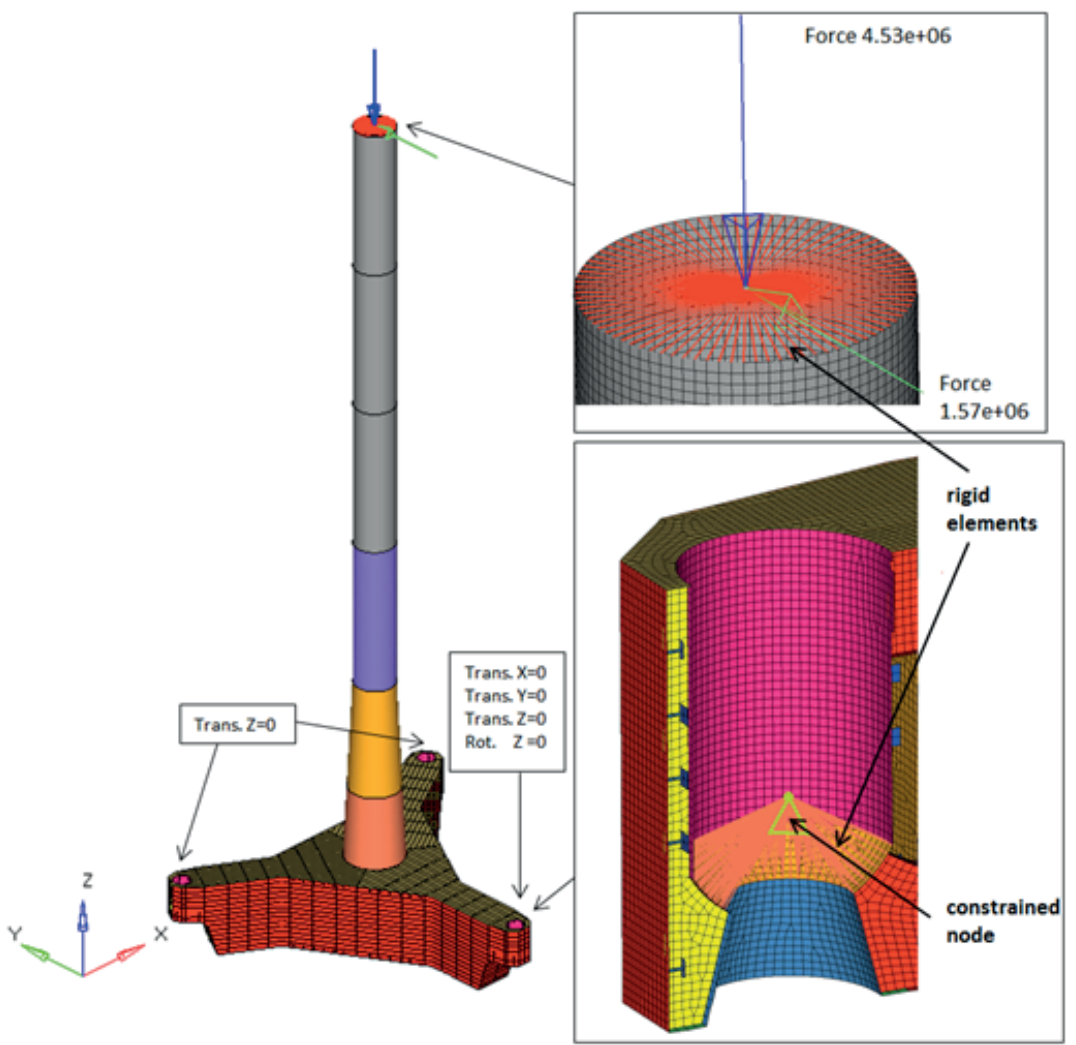

Fig. 11. Model fixation. calculation data. This load generates a bending moment, which is a significant load on the structure. The assumed load distribution has no significant effect on the local strength of the structure, and significantly facilitates the preparation of the computational data.

Earth acceleration is applied to the opposite redirection in the $Z$ direction. In addition, in the $\mathrm{Y}$ direction, all the elements of the structure have a predetermined acceleration of $3.41 \mathrm{~m} / \mathrm{s}^{2}$. The values of generated inertial forces acting on a given segment of a structure are shown in Figure 10.

Hydrostatic pressure was applied in the normal direction to the plating elements of the platform and the column in accordance with the assumptions in Chapter 4.

\section{MES CALCULATIONS}

Structural strength calculations have been made in the linear range. HyperWorks v13 software, manufactured by Altair was used., HyperMesh software was used as a preprocessor. Calculations were made using the Optistruct solver, while results were generated using the

\section{LOAD IMPLEMENTATION}

According to the above mentioned, the MES model was put under load at the centre point at the top of the wind tower with the following forces:

- $\quad$ vertical force acting on the reverse $\mathrm{Z}$ direction and 4.53 MN from the mass of the nacelle and rotor;

- a transverse force acting on the Y direction of $0.45 \mathrm{MN}$ being the value of the turbine's thrust;

- Transverse force acting on the Y direction of $1.57 \mathrm{MN}$ as the inertia mass of the nacelle and rotor mass for the calculated acceleration of the structure of $3.41 \mathrm{~m} / \mathrm{s}^{2}$.

The hydrodynamic load of the structure according to the assumptions presented in the previous chapter was applied to the nodes in the Y direction. The model grid was split at the level of the segments from which the node numbers were read. Each of the segment nodes applied with the force that was determined by dividing the CFD simulation by the total load of the segment by the number of nodes. The accepted way of implementing the load has no real influence on the local strength of the structure, and significantly facilitates the preparation of the

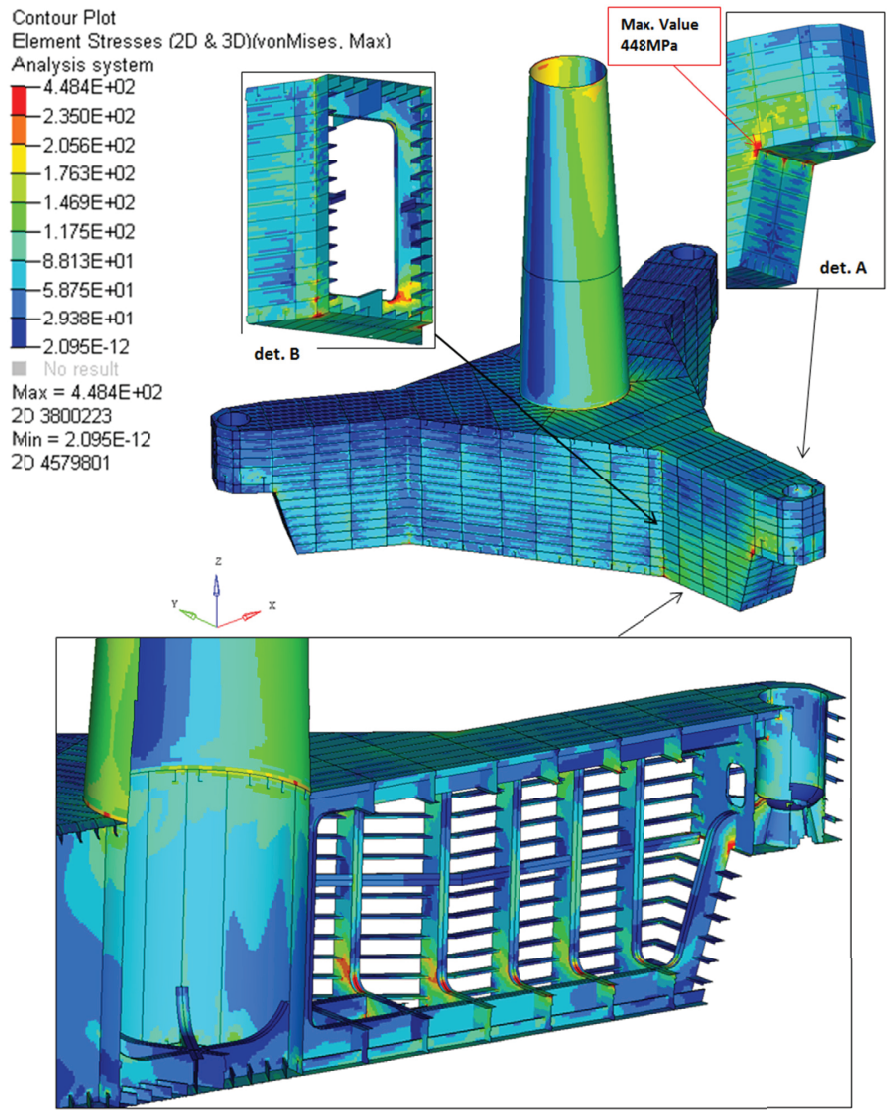

Fig. 12. Equivalent stresses [MPa] 
HyperView postprocessor. The simulation was performed on a $\mathrm{PC}$ equipped with a quad-core 64 -bit Intel ${ }^{\circledR}$ i7 processor with $3.40 \mathrm{GHz}, 16 \mathrm{~GB}$ of DDR3 RAM and an 840 PRO SSD. Calculations for construction in the final stages of geometry modification, where the number of surface finite elements was about 0.8 million lasted about 10 minutes.

\section{CALCULATION OF THE STRENGTH OF THE PRE-CONSTRUCTION}

The calculations made for the initial form of the structure, shown in Figure 8, were meant to indicate the critical areas of the proposed structure. It should be added that for the previously described method of loading the structure, the most stressed part of the structure is the arm in the direction of the transverse force Fy. In this case, the highest bending moment is generated on the indicated arm of the platform in comparison to the other arms.

In the above figure it can be seen that the region of occurrence of the greatest stress, which reaches $448 \mathrm{MPa}$ is the portion of the hull at the junction node of the primary arm mounting structure (det. A on FIG. 12). The stress concentration is also visible on the web of the main girder connecting the arm portion of the regular fixing location of the tendon. In this case, the cause of high stress is too rapid change in the shape of geometry of such a large load which are local forces in the tendons. Moreover, considerably higher than the yield strength of the carbon steel $(235 \mathrm{MPa})$ present in the webs and agents frames in the regions of changing the direction of the stiffener.

\section{MODIFICATIONS OF CONSTRUCTION}

Because of the high stress values at the points of the analyzed structure, there has been a need for modifications in the most stressed areas where the stresses exceed the permissible values for normal strength steel. The geometric changes in the model introduced in the first modification step are described below. The modified design is shown in Figure 13.

- Based on the results obtained, it was found that the design at the transition site of the regular arm shape into the bearing seat should be significantly redesigned. It was decided that the sloping section of the inclined plating to the horizontal support plate for the stiffening of the bearing shell must be rounded to avoid high stress concentrations at the node. This plating was joined together through a rounded sheet of $40 \mathrm{~mm}$ thick and with a bending radius of $1500 \mathrm{~mm}$.

- The shape of the central web is adjusted to the rounded shape of the above-mentioned plating. In addition, the thickness of the web at this point was increased from $20 \mathrm{~mm}$ to $40 \mathrm{~mm}$.
- The passage of the lateral plating of the central part of the platform and arm has been thickened over the whole circumference. An increase in the sheet thickness to $40 \mathrm{~mm}$ included the plating band stretched between the two frame stiffeners shown in Figure 13.

- The thickness of the plating in the centre column area was increased to $30 \mathrm{~mm}$.

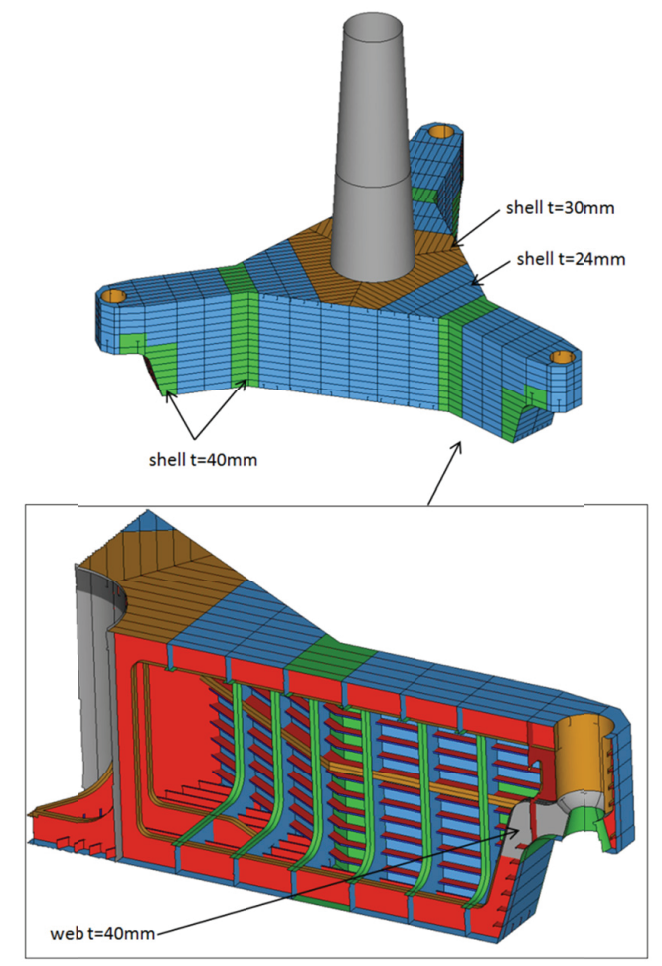

Fig. 13. Construction changes - first stage.

The calculation results for the modified support structure are shown in Figure 14. The scale has been set so that the red colour indicates the stresses above $235 \mathrm{MPa}$.

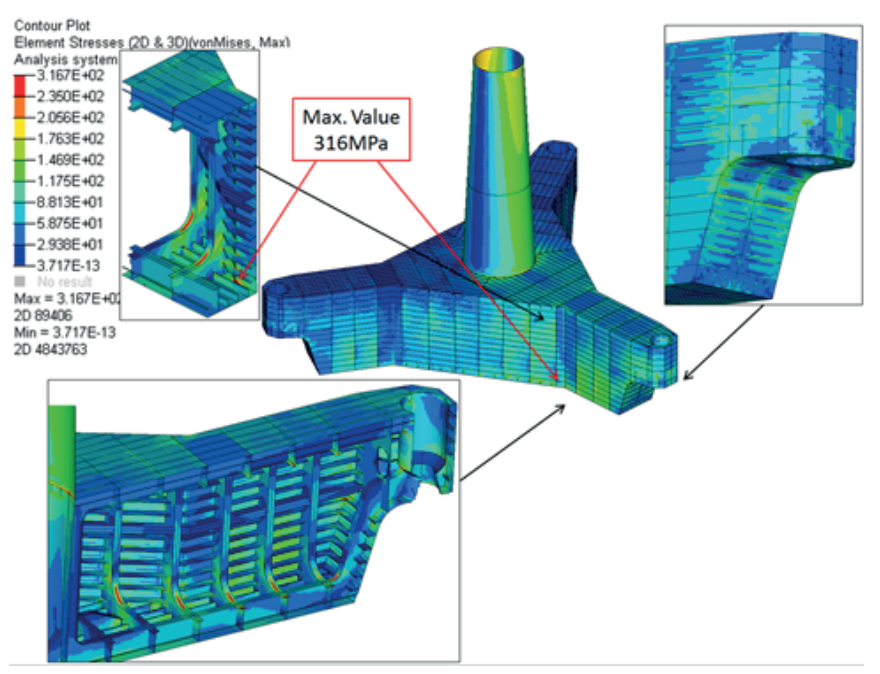

Fig 14. Equivalent stresses after changes [MPa]. 
The changes made reduced the maximum stress reduced to about $316 \mathrm{MPa}$, also, the area of stresses beyond the yield strength decreased. In the figure above, it can be observed that, as expected, modifications introduced in the structure restriction region have worked very favourably, distributing the stresses in a mild manner.

Maximum stresses occurred in the corner connecting the side wall plating and the bottom of the platform. The cause of the concentration in this area is the sharp change of shape at the point of contact of the falling platelets of the side plating of the regular platform with the lateral arm of the arm. Visible areas of the high stress concentration are still the frame parts. On the basis of the results obtained, the geometry was to be transformed further, thus reducing the stresses in excess of $235 \mathrm{MPa}$.

\section{FINAL STAGE OF MODIFICATION. VERIFICATION CALCULATIONS.}

The last modification shown in Figure 15 has led to a structure that meets the criteria in terms of strength. Due to still high stress in the area of the central column passage through the top plating, it was decided that this section of the column would be a $70 \mathrm{~mm}$ thick ring and $2 \mathrm{~m}$ high deposited $1 \mathrm{~m}$ on either side of the plating. Thickness of the conical column has been increased to $60 \mathrm{~mm}$. Enclosures in more stressed areas (blue) were given a thickness of $36 \mathrm{~mm}$. The brackets of the frame stiffeners were modified. In areas of rounded passages, inserts of thickness $50 \mathrm{~mm}$ were used, in addition, these places were supported by brackets. In the longitudinal girders, the relief openings have been made in the less stressed webs significantly reducing the mass of the longitudinal stiffeners. The total weight of the structure after the variations shown was $1456 \mathrm{t}$.

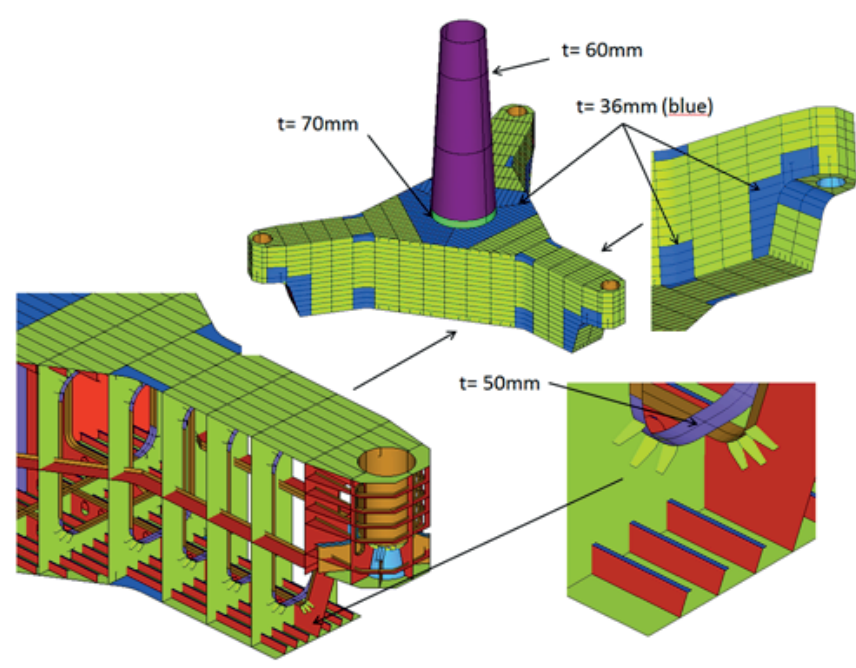

Fig. 15. Support structure after optimization.

Figures 16 and 17 show the stresses and deformations of the final version of the support structure. Based on their analysis, it can be stated that the highest stresses of $286 \mathrm{MPa}$ occur only on the individual finite elements of the model in the region of joining the top shell to the column. It should be noted here that calculations using coating elements (2D) in areas of sudden shape change may exhibit unnatural stresses. As a result, the authors allow for a slight excess of stresses in the belt of one element width from the edge joining the two parts of the structure. In order to obtain more reliable results at the junctions of major structural parts, additional local analyses of selected regions using $3 \mathrm{D}$ elements should be performed. Ensuring structural strength in areas where the stress exceeds $235 \mathrm{MPa}$, for the assumed load system, will be achieved by using high strength steels. The maximum displacement that occurred on the turret mount flange was $115 \mathrm{~mm}$

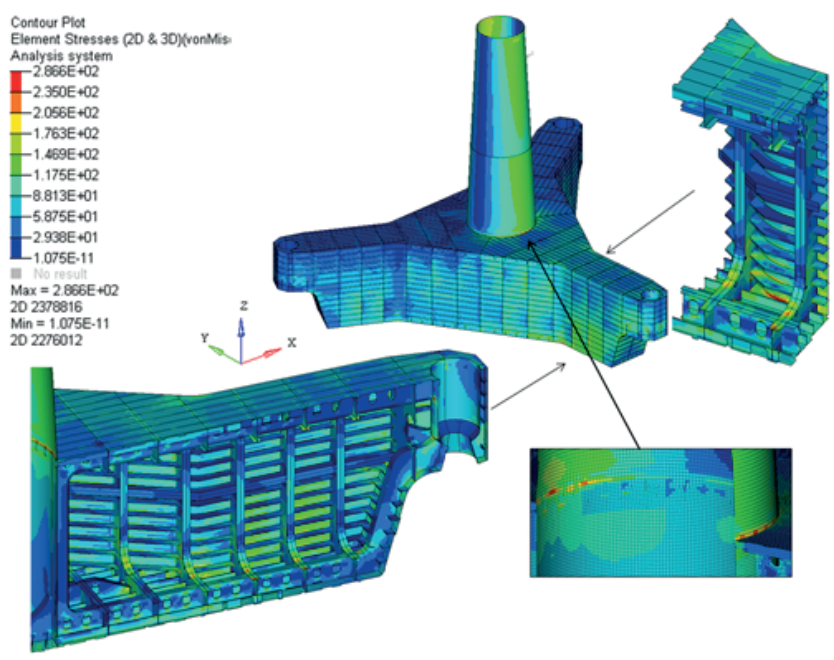

Fig.16. Reduced stress [MPa]

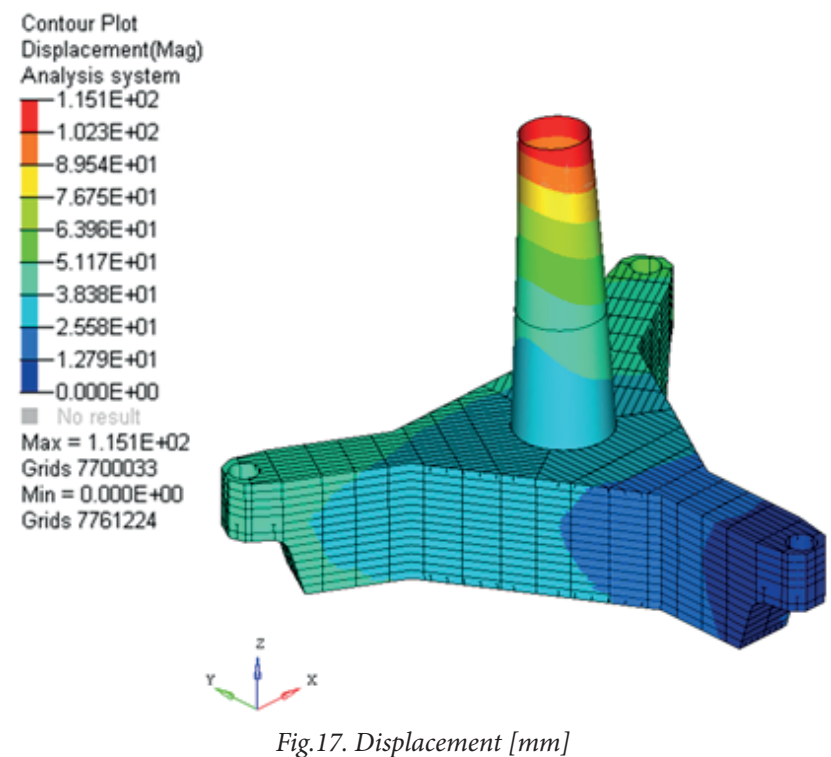

Fig.17. Displacement [mm] 


\section{SUMMARY}

The present article deals with current and complex issues related to the design of marine facilities under high power wind farms. The authors undertook the task of designing a preliminary steel variant of the TLP platform designed for anchoring on the Baltic area with a depth of about $60 \mathrm{~m}$. The next steps in the design of the platform design were presented, which was to provide ad hoc strength at maximum load that could occur during marine operation. Preliminary strength calculations indicated the critical structural nodes that had to be modified. After the changes described in Chapter 10 on structural modification, the stress areas exceeding the limit values for normal strength steel decreased considerably. The next step was the changes in the thickness of the plating and stiffeners to larger ones in the stressed areas and the reduction of the thickness in the unloaded areas. The authors are aware that for this type of construction designed as a marine wind turbine support structure, fatigue calculations are required to take account of the impact of environmental loads. Such calculations will be carried out in the next stage of the project.

In the presented platform more than $90 \%$ of the weight of the structure can be made of normal steel hull strength (class NV B - Re235 in accordance with [19]). It raises the advantages of this project, which has already attracted interest among representatives of investors of wind farms. In the most demanding areas, NV-class steel, E 36 - Re 355 as per [19] must be used.

According to the authors, this article presents a number of issues related to the design of steel naval constructions very useful for designers, researchers and investors of this type of objects. In addition, it allows to estimate the level of technical and material costs related to their execution.

\section{ACKNOWLEDGMENT}

FEM analysis has been performed with HYPER WORKS software. Calculations were carried out at the Academic Computer Center in Gdańsk (TASK).

This research was supported by The Polish National Centre for Research and Development (NCBR) under the project "WIND-TU-PLA" ERA-NET MARTEC II (Agreement No. MARTECII/1/2014)

\section{REFERENCES}

1. M. Deja, M.S. Siemiątkowski: Feature-based generation of machining process plans for optimised parts manufacture. Journal of Intelligent Manufacturing August 2013, Volume 24, Issue 4, pp 831-846.

2. Niklas K., Kozak J.: Experimental investigation of SteelConcrete-Polymer composite barrier for the ship internal tank construction. OCEAN ENGINEERING. -Vol. 111, (2016), s.449-460
3. Hirt Ł., Lampart P.: Complex multidisciplinary optimization of turbine blading systems. ARCHIVES OF MECHANICS. -Vol. 64, nr. 2 (2012), s.153-175

4. Sabik A., Kreja I.: Large thermo-elastic displacement and stability FEM analysis of multilayered plates and shells. THIN-WALLED STRUCTURES. -Vol. 71, (2013), pp.119-133.

5. Kahsin M., Łuczak M.: NUMERICAL MODEL QUALITY ASSESSMENT OF OFFSHORE WIND TURBINE SUPPORTING STRUCTURE BASED ON EXPERIMENTAL DATA. Structural Health Monitoring 2015: System Reliability for Verification and Implementation: Proceedings of the 10th International Workshop on Structural Health Monitoring.- Vol. 1/ ed. Fu-Kuo Chang, Fotis Kopsaftopoulos 439 North Duke Street - Lancaster, PA 17602-4967, U.S.A. : DEStech Publications, Inc., 2015, s.2817-2824

6. Kahsin M., Luczak M., Peeters B.: Use and assessment of preliminary FE model results within testing process of offshore windturbine supporting structure. EURODYN 2014: IX INTERNATIONAL CONFERENCE ON STRUCTURAL DYNAMICS, Book Series: EURODYN-International Conference on Structural Dynamics, Pages: 3659-3666

7. Łuczak M., Manzato S., Peeters B., Branner K., Berring P., Kahsin M.: Updating Finite Element Model of a Wind Turbine Blade Section Using Experimental Modal Analysis Results. SHOCK AND VIBRATION. -Vol. 2014, iss. 1 (2014), s.71-82

8. Brommundt M., Krause L.,Merz K., Muskulus M.: Mooring system optimization for floating wind turbines using frequency domain analysis. Energy Procedia 24 (2012) 289-296

9. Karimirad M., Moan T.: A simplified method for coupled analysis of floating offshore wind turbines. Marine Structures 27 (2012) 45-63

10. Jeon S.H., Cho Y.U., Seo M.W., Cho J.R., Jeong W.B.: Dynamic response of floating substructure of spar-type offshore wind turbine with catenary mooring cables. Ocean Engineering 72 (2013) 356-364

11. Bachynski E.E., Moan T.: Design considerations for tension leg platform wind turbines. Marine Structures 29 (2012) 89-114

12. Adam F.,Myland T., Schuldt B., Großmann J., Dahlhaus F.: Evaluation of internal force superposition on a TLP for wind turbines. Renewable Energy, Volume 71, November 2014, Pages 271-275 
13. Adam F., Ritschel U., Plumridge E., Großmann J.:PreDesign of a TLP steel-concrete composite substructure for a $6 \mathrm{MW}$ wind turbine as a way to essential cost-reduction. Conference proceedings RENEW, 2016, Lisbon

14. DNV-OS-J103 Design of Floating Wind Turbine Structures. JUNE 2013

15. https://www.senvion.com/global/en/wind-energysolutions/ wind-turbines/ $6 \mathrm{xm} / 62 \mathrm{~m} 126 /$

16. Jonkman J., Butterfield S., Musial W., Scot G.: Definition of a 5-MW Reference Wind Turbine for Offshore System Development. Technical Report NREL/TP-500-38060 February 2009

17. Sarpkaya T.: Wave forces on offshore structures, Cambridge University Press, 2010

18. Dymarski P., Ciba E., Marcinkowski T.: Effective method for determining environmental loads on supporting structures for offshore wind turbines. POLISH MARITIME RESEARCH 1(89) 2016 Vol. 23; pp. 52-60 10.1515/ pomr-2016-0008

19. DNV-OS-J101 Design of Offshore Wind Turbine Structures. MAY 2014
CONTACT WITH THE AUTHOR

Jędrzej Żywicki

e-mail: jedzywic@pg.gda.pl

Paweł Dymarski

Ewelina Ciba

Czesław Dymarski

Gdańsk University of Technology

11/12 Narutowicza St. 80 - 233 Gdańsk

Poland 